\title{
Fleet Planning Decision-Making: Two-Stage Optimization with Slot Purchase
}

\author{
Lay Eng Teoh ${ }^{1}$ and Hooi Ling Khoo ${ }^{2}$ \\ ${ }^{1}$ Department of Mathematical and Actuarial Sciences, Lee Kong Chian Faculty of Engineering and Science, \\ Universiti Tunku Abdul Rahman, Building KB, Level 8, Jalan Sungai Long, Bandar Sungai Long, Cheras, \\ 43000 Kajang, Selangor, Malaysia \\ ${ }^{2}$ Department of Civil Engineering, Lee Kong Chian Faculty of Engineering and Science, Universiti Tunku Abdul Rahman, \\ Building KB, Level 8, Jalan Sungai Long, Bandar Sungai Long, Cheras, 43000 Kajang, Selangor, Malaysia \\ Correspondence should be addressed to Lay Eng Teoh; teohle@utar.edu.my
}

Received 18 December 2015; Revised 6 May 2016; Accepted 12 May 2016

Academic Editor: Zhan Kang

Copyright ( 2016 L. E. Teoh and H. L. Khoo. This is an open access article distributed under the Creative Commons Attribution License, which permits unrestricted use, distribution, and reproduction in any medium, provided the original work is properly cited.

Essentially, strategic fleet planning is vital for airlines to yield a higher profit margin while providing a desired service frequency to meet stochastic demand. In contrast to most studies that did not consider slot purchase which would affect the service frequency determination of airlines, this paper proposes a novel approach to solve the fleet planning problem subject to various operational constraints. A two-stage fleet planning model is formulated in which the first stage selects the individual operating route that requires slot purchase for network expansions while the second stage, in the form of probabilistic dynamic programming model, determines the quantity and type of aircraft (with the corresponding service frequency) to meet the demand profitably. By analyzing an illustrative case study (with 38 international routes), the results show that the incorporation of slot purchase in fleet planning is beneficial to airlines in achieving economic and social sustainability. The developed model is practically viable for airlines not only to provide a better service quality (via a higher service frequency) to meet more demand but also to obtain a higher revenue and profit margin, by making an optimal slot purchase and fleet planning decision throughout the long-term planning horizon.

\section{Introduction}

Fleet planning is carried out by airlines to determine the quantity and type of aircraft to be purchased or leased in order to provide a profitable service throughout the longterm planning horizon. A strategic fleet planning is vital as it has a great impact on the economic efficiency of airlines [1]. In addition, the supply of oversized aircraft can implicate an increased cost while a composition of undersized aircraft results not only in unsatisfied demand but also in substantial financial loss to airlines [2-4].

Travel demand and service frequency are found to be two influential factors in fleet planning [5-8]. In other words, there is a close relationship between the type of aircraft, aircraft quantity, travel demand of passengers, and the service frequency in fleet planning. Past research had shown that if travel demand is estimated stochastically to account for uncertainty, the optimal solutions are more accurate and reliable $[6,9,10]$. In addition, fleet planning has an added advantage if the demand of varying classes of passengers (i.e., business and economy) is considered [11, 12]. This is crucial for the airlines to expand their services particularly to serve new destinations.

For airlines, service frequency determination is vital to assure operating effectiveness [13]. Without this element, the resultant fleet planning decision may not be appropriate to support the current and new operating networks under stochastic demand. However, the service frequency of airlines is strictly constrained by the regulatory limits, especially with the arrival/departure restriction slots in some particular airports. For instance, the operating quota of aircraft movements at Orly International Airport, France, 
is 36 takeoffs and 34 landings per hour during peak hours [14]. As such, the strategy of airlines to provide a higher service frequency (to meet increasing demand) may not be workable, unless prior approval (e.g., via slot purchase) is obtained. In case an increasing service frequency is not feasible for airlines to meet the demand increment, airlines may need to select a specific aircraft type to accommodate the demand increment. Yet, the selection of aircraft by airlines is highly dependent on the aircraft specification (type) which is closely associated with the corresponding service frequency. As such, it is necessary for service frequency to be included in fleet planning. Practically, additional service frequency could be obtained by incorporating slot purchase when making optimal fleet planning decision. The lack of desired slots for additional service frequency may lead to a loss in revenue due to the inability of airlines to meet passenger's demand.

Based on the IATA system, slot purchase (or slot allocation) is made twice a year during the IATA Scheduling Conference [12]. Subsequently, secondary slot trading was introduced based on the airline's willingness to pay for slots [15] for which the slot price is commonly airport specific and greatly influenced by the time of the day, airline regulation, travel demand, and so forth [16]. To incorporate slot purchase into fleet planning, this paper formulates a two-stage fleet planning model in which the first stage aims to find the optimal choice of the operating route that requires slot purchase to meet stochastic demand while the second stage subsequently determines the optimal quantity of the respective aircraft type (with corresponding service frequency) for each operating period. To capture the airline's business principles in a better manner, both stages include the specific airfare of the class of passengers to obtain the optimal solutions.

\section{Literature Review}

2.1. Slot Purchase. Many past studies investigated the benefits of slot purchase by airlines. In particular, Mehndiratta and Kiefer [17] estimated the impact of slot controls with a market-based allocation mechanism while Brueckner [18] discussed the benefits of slot purchase to manage airport congestion by adopting price and quantity-based approaches. In practice, slot purchase is found to be extremely useful to increase flight frequency and operations efficiency [18], in order to reduce delay $[17,19,20]$, and to meet fluctuating demand [21] as well as to generate more profit $[11,12]$. Besides, Basso and Zhang [22] in comparing the congestion pricing and slot trading revealed that the total air traffic is higher under the slot auctions. However, congestion pricing may be strongly preferred over slot auction if airport profits matter substantially, especially when airlines are asymmetric. Fukui [21] used the regression analysis to examine whether slotholding carriers have resulted in restricted market entry and service expansion by other carriers. The results highlighted that it is necessary to design additional enhancement mechanisms for the slot trading system in order to yield more benefits to airlines. In addition, Babic and Kalic $[11,12]$ optimized the slot purchase decision-making (with maximum revenue) to solve flight scheduling problem. They found that slot purchase could increase new destinations, flight frequency, and schedule connectivity.

As revealed by the aforementioned past studies, it could be seen that slot purchase is beneficial to airlines in assuring more profit, via a higher service frequency in meeting more demand. Therefore, service frequency and slot purchase need to be considered simultaneously in solving the fleet planning problem optimally.

2.2. Service Frequency Determination. Pitfield et al. [7] and Takebayashi [23] showed that airlines would tend to increase flight frequency and decrease aircraft size when demand increases and also when airport runway capacity expands. In order to determine flight frequency, Teodorović [24] simulated the service frequency fluctuation by assigning lower and upper limits that can be used in the fleet planning model while Listes and Dekker [6] solved the fleet assignment problem by selecting a particular aircraft type to meet travel demand with the assumption of fixed service frequency. The limitation of these studies is that flight frequency determination has no clear indication on how to meet demand increment if it requires additional service frequency that exceeds the upper limit. In addition, Givoni and Rietveld [25] analyzed the environmental impacts on the selection of aircraft size and service frequency. They revealed that airlines need to operate at a lower service frequency and also with larger aircraft size if they wish to minimize aircraft emission and noise. More recently, Khoo and Teoh [26] considered the annual service frequency of airlines in their fleet planning optimization model. However, the forecasted annual flight frequency of airlines which did not capture the control of flight frequency explicitly may not be practical under circumstances, especially when the number of flights of airlines is limited at busy airports.

For other studies, service frequency is optimized in maximizing the profit margin of the airlines. However, the travel demand in these studies is either assumed to be inelastic [27] or predetermined without considering the occurrence of uncertainty [5]. Besides, there is only a single type of aircraft that is being considered for optimization purpose [28]. Specifically, Hansen [27] determined the service frequency for the respective airline given the flight frequency of the competing airlines. However, he assumed fixed airfares which could imply an inelastic demand with respect to price and service. Teodorović et al. [28] determined the flight frequency by applying the linear programming. Yet, the preference index value (for route candidates' selection) is arbitrarily assigned to optimize service frequency (with varying fuzzy numbers). To optimize the airline's service frequency, Hsu and Wen [5] examined the passengers' flight selection behavior specifically. They showed that when travel time increases, airline could increase flight frequency while raising basic airfares. However, the solutions depend on the initially predetermined market shares which might be underestimated. Besides, there is no clear explanation on how to increase flight frequency in practice.

2.3. A Brief Review of Fleet Planning. In order to make fleet planning decision, Dožić and Kalić [8] developed a 
three-stage robust model to determine the aircraft size and the corresponding composition, particularly for short- and medium-haul flights. The optimal fleet planning decision is made by using the fuzzy logic and heuristic and analytic approaches. However, the developed model is not applicable for long-haul flight. Besides, the quantity of aircraft is determined solely based on the heuristic technique (instead of optimization). Hsu et al. [9] developed a stochastic dynamic programming model to purchase, lease, and dispose aircraft optimally. The results show that airlines tend to lease aircraft to meet demand fluctuation. Besides, the fleet composition is formed by using a single type of aircraft. By considering airlines alliance, Hsu et al. [10] formulated a dynamic programming model to purchase, lease, and dispose aircraft. It was found that the airline can achieve more cost savings through interactive bargaining (for aircraft acquisition/leasing). However, Hsu et al. [9, 10] did not tackle the occurrence of unexpected events in demand modeling. Furthermore, their models might be too simplistic by capturing demand as the sole constraint.

Wei and Hansen [29] built a nested logit model to investigate the influence of aircraft size, service frequency, seat availability, and airfare based on passenger demand. However, they only focused on the demand aspect without considering the necessity to meet traveler's expectation with an adequate aircraft composition. Later, Wei and Hansen [30] formulated the game-theoretic model to inspect the airline's decision-making on aircraft size and flight frequency under competitive environment. However, they assumed that the competing airlines have a fixed aircraft choice and a particular airline has some dominance in the market. This may not be realistic. Besides, the airline's decision-making on aircraft size and service frequency is made separately. With these assumptions, the reliability and applicability of their model might be questionable to certain extent. Similarly, Wei [31] employed a one-shot simultaneous game theory model to analyze the airline's decision on aircraft choice and service frequency in duopoly markets. The competing airlines were assumed to select aircraft size and service frequency concurrently. It is also assumed that they know all the available choices and resultant profit for each other. This might not be practical. More recently, Teoh [32] solved fleet planning problem by incorporating slot purchase. In contrast to this paper, she developed two optimization models to meet the demand of the existing and new operating network of airline. Although the developed models are able to determine the optimal quantity of the respective aircraft type (by optimizing different model for the current and new operating network), slot utilization constraint is not taken into consideration. This may not fully utilize the purchased slot at a satisfactory level.

In summary, there is no existing study that could provide a proper mechanism to assist airlines to provide additional service frequency under numerous practical constraints. Many existing studies ignored the availability of slot purchase in meeting stochastic demand. This may result in the unfeasibility of airline's fleet supply. Furthermore, some assumptions from past studies might curb the applicability of the existing approaches in solving the fleet planning problem optimally.

\section{Two-Stage Fleet Planning Model}

Let $\mathbf{F}$ be the operating system of the airline which is formed by the current operating networks, $F_{\mathrm{ex}}$, and new operating network, $F_{\mathrm{nw}}$; that is, $F_{\mathrm{ex}} \cup F_{\mathrm{nw}}=\mathbf{F}$. Specifically, $F_{\mathrm{ex}} \cap F_{\mathrm{nw}}=\varnothing$ for which $F_{\mathrm{ex}}, F_{\mathrm{nw}} \in \mathbf{F}$. To support the current and new operating networks at a desired service level, two-stage fleet planning decision model is developed accordingly for which the first stage (stage 1), that is, slot purchase decision model, plays the role of selecting the operating route (flight) that qualifies slot purchase for network expansions. The subsequent stage (stage 2 ), that is, fleet planning decision model, aims to optimize aircraft acquisition and leasing by determining the optimal quantity of the respective aircraft type to support the entire operating system throughout the planning horizon. The twostage fleet planning model is formulated mainly to capture the two different forms of decision-making of the airlines; that is, slot purchase decision model (stage 1) corresponds to tactical strategy that is to be made not only to meet increasing demand for the current operating networks but also to service new network expansion. On the other hand, fleet planning decision model (stage 2) corresponds with the establishment of long-term fleet planning (aircraft supply) to meet the fluctuating demand which may increase or decrease or undergo no change under uncertainty. In stage 2, although the optimal solutions could be obtained, the optimal decision for the next operating period is unknown due to uncertainty [33].

For $n$ types of aircraft (at age $y$ ), the notations used for operating period $t$ are listed in Abbreviations.

\subsection{Stage 1: Slot Purchase Decision Model}

3.1.1. Constraints. To make a slot purchase decision for the current and new network expansions (for which $t=$ $1,2, \ldots, T)$, five practical constraints are considered as follows.

Slot Purchase Budget Constraint. In order to ensure that slot purchase is financially feasible for the airlines, the slot price of a particular operating route (flight) should not be more than what the airlines are willing to pay. By considering the airline's allocated budget for slot purchase, this constraint can be formed as follows:

$$
C_{F_{i}} \leq W_{F_{i}} \quad \text { for } F_{i} \in F_{\mathrm{ex}}, F_{\mathrm{nw}}
$$

Notably, constraint (1) is formed mainly to support the slot purchase decision-making (but not aircraft acquisition/leasing decision) at the operating airports, that is, both airports that are operating aircraft that departs and arrives.

Slot Determination Constraint. In view of the fact that the slot purchase is needed primarily to support the increasing demand, the respective operating route that qualifies slot purchase (to be decided for slot purchase decision) should be taken into consideration not only based on the level of increasing demand but also based on the airline's current fleet supply in order to meet the stochastic demand desirably. 
Thus, the slot determination constraint for the current operating network, $F_{\mathrm{ex}}$, could be formed as follows:

$$
F_{i}= \begin{cases}1, & \text { if }\left(D_{t, F_{i}}>D_{t-1, F_{i}}\right) \cap\left(D_{t, F_{i}} \geq \sum_{i=1}^{n}\left(\operatorname{LF}_{i, F_{i}}^{t-1}\right)\left(\operatorname{SEAT}_{i, F_{i}}^{t-1}\right)\left(f_{i, F_{i}}^{t-1}\left(D_{t-1, F_{i}}^{S}, A_{t-1}^{i}\right)\right)\right) \text { for } F_{i} \in F_{\mathrm{ex}} \\ 0, & \text { otherwise. }\end{cases}
$$

New Network Operation Constraint. In order to assure that the expansion of new network, $F_{n w}$, would be operated profitably, airline needs to know when is the right (best) time to run new operating routes in order to meet the stochastic demand at a desired service level. Ideally, a profitable new route will be operated, right on time, to attain the highest demand level. As such, new network operation constraint could be outlined as follows:

$$
F_{i}= \begin{cases}1, & D_{t, F_{i}}=\underset{\forall t}{\arg \max }\left\{D_{t, F_{i}}\right\} \text { for } F_{i} \in F_{\text {nw }} \neq \varnothing \\ 0, & \text { otherwise. }\end{cases}
$$

Aircraft Execution Constraint. To ensure that qualified operating route for slot purchase would be operated during airport working hours, aircraft execution constraint could be formed as follows:

$$
\begin{aligned}
\text { open } \leq & \mathrm{TUN}_{n, F_{i}, k}^{t}+\mathrm{BLK}_{n, F_{i}}^{t}+\mathrm{TUN}_{n, F_{i}, z}^{t}+\mathrm{BLK}_{n, F_{i}}^{t} \\
& +\mathrm{TUN}_{n, F_{i}, k}^{t} \leq \text { close }
\end{aligned}
$$

$$
\text { for } \forall n, k, z, F_{i} \in F_{\mathrm{ex}}, F_{\mathrm{nw}} \text {, }
$$

for which the flight (operating route $F_{i}$ ) departs from airport $k$ and arrives at airport $z$. This constraint is important mainly due to prior approval (permission) of aircraft operations at some airports, especially when aircraft arrival or departure needs to be made before or after the standard operation hours at airport. Besides, this constraint also plays a role in assuring that aircraft operation is practically feasible at both operating airports; that is, the airline has to secure the slot allocation at both airports in order to meet the demand of passengers.

Slot Utilization Constraint. In order to attain a high utilization rate of the slot purchase (by providing a particular flight frequency) under such a competitive environment of the airline industry, the slot utilization constraint of airline (in terms of the estimated service frequency) could be outlined as below:

$$
\frac{\mathrm{E}\left(f_{F_{i}}^{t}\right)}{\mathrm{E}\left(f_{F_{i}}^{t-1}\right)} \geq 80 \% \text { for } F_{i} \in F_{\mathrm{ex}}, F_{\mathrm{nw}}
$$

For this constraint, the value of $80 \%$ is chosen primarily due to the "grandfather rights," a traditional IATA-based slot allocation system, which is widely used in the European Union. This constraint plays the role of securing the slot purchase of a particular operating period by assuring that the estimated flight frequency of airline for a particular period would be at least $80 \%$ in comparison to previous period $[34,35]$. This is important to ensure high slot utilization.

3.1.2. Formulation of Slot Purchase Decision Model. To make an optimal slot purchase decision, the airfare of each class of passenger is considered specifically with the aim of obtaining maximum operational revenue of a particular operating route under stochastic demand. For the airlines, slot purchase is required particularly not only to meet the demand increment for the current operating network but also for new network expansion. In other words, the lack of desired slots may lead to the loss of airline revenue due to the inability to meet passenger's demand $[11,12]$ and hence revenue maximization is of utmost importance. Therefore, the main objective of the slot purchase decision model is to maximize the airline's operational revenue, $R_{t, F_{i}}$. In general, the slot purchase decision model (at stage 1) could be formed as follows:

$$
\begin{aligned}
& R_{t, F_{i}}=\max _{F_{i} \in F_{\mathrm{ex}}, F_{\mathrm{nw}}}\left\{b _ { \mathrm { ex } } \left(c_{\mathrm{biz}, F_{i}}\left(\Delta p_{\mathrm{biz}, F_{i}}^{*}\right)+c_{\mathrm{fec}, F_{i}}\left(\Delta p_{\mathrm{fec}, F_{i}}^{*}\right)\right.\right. \\
& \left.\quad+c_{\mathrm{dec}, F_{i}}\left(\Delta p_{\mathrm{dec}, F_{i}}^{*}\right)\right)+b_{\mathrm{nw}}\left(c_{\mathrm{biz}, F_{i}}\left(\Delta p_{\mathrm{biz}, F_{i}}^{*}\right)\right. \\
& \left.\left.\quad+c_{\mathrm{fec}, F_{i}}\left(\Delta p_{\mathrm{fec}, F_{i}}^{*}\right)+c_{\mathrm{dec}, F_{i}}\left(\Delta p_{\mathrm{dec}, F_{i}}^{*}\right)\right)\right\}
\end{aligned}
$$

subject to the practical constraints (1)-(5). In model (6), the component of $\Delta p_{\mathrm{biz}, F_{i}}^{*}=\operatorname{Biz}_{\%}\left(D_{t, F_{i}}^{*}\right), \Delta p_{\mathrm{fec}, F_{i}}^{*}=\operatorname{Fec}_{\%}\left(D_{t, F_{i}}^{*}\right)$, and $\Delta p_{\mathrm{dec}, F_{i}}^{*}=\operatorname{Dec}_{\%}\left(D_{t, F_{i}}^{*}\right)$ is approximated to meet the respective demand level of each passenger's class (business class and economy class with full fare and discounted fare) which can be met by making optimal slot purchase decision. For different class of passenger, the demand increment (for the current operating network) which is supported by new slot (via optimal slot purchase decision) is estimated to be $D_{t, F_{i}}^{*}=D_{t, F_{i}}-D_{t-1, F_{i}}$ while $D_{t-1, F_{i}}=0$ for new network expansion. Specifically, the demand level of a particular operating period, $D_{t, F_{i}}$, could be obtained accordingly based on the 5-step stochastic demand modeling framework of Khoo and Teoh [26]. In model (6), the binary variables of the current and new operating networks are indicated as $b_{\mathrm{ex}}$ and $b_{\mathrm{nw}}$, respectively, for which

$$
\begin{aligned}
& b_{\mathrm{ex}}= \begin{cases}1, & \text { if } F_{i}=1 \text { for } F_{i} \in F_{\mathrm{ex}} \\
0, & \text { otherwise, }\end{cases} \\
& b_{\mathrm{nw}}= \begin{cases}1, & \text { if } F_{i}=1 \text { for } F_{i} \in F_{\mathrm{nw}} \\
0, & \text { otherwise. }\end{cases}
\end{aligned}
$$




\subsection{Stage 2: Fleet Planning Decision Model}

3.2.1. Constraints. Ten practical constraints are considered necessarily to solve the fleet planning problem. These constraints are outlined as follows (for which $t=1,2, \ldots, T$ ).

Aircraft Operations Constraint. In compliance with regulated traffic rights at some airports, the aircraft operations of airlines are under control; that is, service frequency of a particular operating route cannot exceed a certain limit. Under this circumstance, aircraft utilization of the airlines (subject to maximum utilization) of each operating route can be expressed as follows:

$$
\begin{array}{r}
\left\lfloor\frac{\mathrm{AVT}_{n, F_{i}}^{t}}{\mathrm{BLK}_{n, F_{i}}^{t}+\mathrm{TUN}_{n, F_{i}, k}^{t}}\right\rfloor \times \mathrm{EFF}_{t} \leq \mathrm{MXU}_{n, F_{i}}^{t}+\mathrm{A}_{n, F_{i}}^{t} \\
\text { for } \forall t, n, k, F_{i} .
\end{array}
$$

Specifically, the RHS of (8) shows that additional service frequency that resulted from slot purchase decision, $\mathrm{A} f_{n, F_{i}}^{t}$, provides a greater control for the airlines to provide more service frequency to meet stochastic demand. In this case, if slot purchase is not made, $\mathrm{A} f_{n, F_{i}}^{t}=0$.

Budget Constraint. For fleet planning purposes, budget constraint assures that the optimal solution is financially feasible for the airlines for which the total acquisition and leasing cost of aircraft do not exceed the allocated budget. This constraint could be expressed as follows:

$$
\sum_{i=1}^{n} \operatorname{purc}_{t i} x_{t i}^{P}+\sum_{i=1}^{n} \text { lease }_{t i} x_{t i}^{L} \leq \operatorname{MAX}_{\text {budget }(t)} \quad \text { for } \forall t .
$$

Demand Constraint. In order to meet travel demand satisfactorily, the demand constraint could be expressed as follows:

$$
\sum_{i=1}^{n} \operatorname{LF}_{i, F_{i}}^{t}\left(\operatorname{SEAT}_{i, F_{i}}^{t}\right)\left(f_{i, F_{i}}^{t}\left(D_{t, F_{i}}^{S}, A_{t}^{i}\right)\right) \geq(1-\alpha) D_{t}^{S}
$$

$$
\text { for } \forall t, s_{h} \in S \text {, }
$$

where $1-\alpha$ is the confidence level in meeting stochastic demand. Note that some operating routes may be operated by several types of aircraft while the level of stochastic demand is modeled by using the demand modeling framework of Khoo and Teoh [26].

Parking Constraint. An aircraft has to be parked at the hangar and/or at the apron of the airport when it is not in operation. As such, the selection of aircraft is sometimes constrained by the geometry layout of the hangar/apron. This constraint is outlined as follows:

$$
\sum_{i=1}^{n} \sum_{y=0}^{m}\left(I_{t i y}^{P}+I_{t i y}^{L}+x_{t i}^{P}+x_{t i}^{L}\right)\left(\text { size }_{i}\right) \leq \text { PARK }_{t} \text { for } \forall t .
$$

Sales of Aircraft Constraint. For some airlines, aging aircraft which is less cost-effective might be sold at the beginning of a certain operating period when airlines make decision to purchase new aircraft. However, the quantity of aircraft sold should not be more than the aircraft owned by airlines. This constraint is expressed as follows:

$$
\operatorname{sold}_{t i y} \leq I_{(t-1) i(y-1)}^{P} \quad \text { for } \forall t, y, i \in n .
$$

Order Delivery Constraint. The production and supply of aircraft manufacturers would affect the availability and delivery status of new aircraft. As such, the quantity of aircraft to be purchased should not be more than the quantity of aircraft available in the market. This constraint could be expressed as follows:

$$
x_{t i}^{P} \leq \mathrm{ORDER}_{t} \quad \text { for } \forall t, i \in n .
$$

Aircraft Range Constraint. Aircraft range (maximum distance flown by aircraft) is important for airlines in view of the fact that the mileage (distance) of each operating route might be different. In order to ascertain the operational feasibility in practice, the constraint to operate the possible aircraft type in terms of aircraft range could be formed as follows:

$$
\mathrm{RG}_{i}>\mathrm{DIS}_{F_{i}} \text { for } \forall i \in n, F_{i} \in F_{\mathrm{ex}}, F_{\mathrm{nw}} \text {. }
$$

Aircraft Homogeneity Constraint. Practically, there is a variety of aircraft types which may be suitable to support the operating networks of the airline. By taking into consideration aircraft homogeneity in fleet composition, the constraint to operate the possible aircraft type can be defined by

$$
x_{t i}^{P}, x_{t i}^{L} \in \mathrm{FC}_{t i} \quad \text { for } \forall t, i \in n,
$$

where $\mathrm{FC}_{t i}$ is the existing variety of airline's fleet composition.

Lead Time Constraint. In practice, airlines would get an agreeable lead time from aircraft manufacturer when they place new order for aircraft acquisition. This constraint is necessary as it denotes when airlines are supposed to order new aircraft. For $n$ types of aircraft, this constraint can be formed as follows:

$$
\mathrm{DLT}_{t i} \geq F^{-1}(1-\beta) \sigma_{\mathrm{LT}}+\mu_{\mathrm{LT}} \quad \text { for } \forall t, i \in n,
$$

for which $F^{-1}(1-\beta)$ is the inverse cumulative probability of $1-\beta$. It is assumed that the lead time possesses a normal distribution (with mean $\mu_{\mathrm{LT}}$ and standard deviation $\sigma_{\mathrm{LT}}$ ).

Selling Time Constraint. In a particular operating period, the airline might sell some aging aircraft considered to be less economical. In such a case, it is vital for the airlines to identify the most suitable time to release aging aircraft for sale. However, the real selling time might be longer than the desired selling time. As such, this constraint is formulated to reduce the possibility of this incident as least as possible. This constraint is defined as follows:

$$
\operatorname{DST}_{t i} \geq F^{-1}(1-\gamma) \sigma_{\mathrm{ST}}+\mu_{\mathrm{ST}} \quad \text { for } \forall t, i \in n,
$$

where $F^{-1}(1-\gamma)$ implies the inverse cumulative probability of $1-\gamma$. It is also assumed that the selling time has a normal distribution (with mean $\mu_{\mathrm{ST}}$ and standard deviation $\sigma_{\mathrm{ST}}$ ). 
3.2.2. Formulation of Fleet Planning Decision Model. The aim of the fleet planning decision model is to maximize the airline's operational profit by determining the optimal quantity and aircraft type that should be purchased/leased to meet stochastic demand. The operational profit of airline could be derived by getting the difference of the total operating cost and total revenue. For operating period $t$, the total revenue, $\operatorname{TR}\left(I_{t}^{P}+I_{t}^{L}\right)$, and the total cost, $\mathrm{TC}\left(I_{t}^{P}+I_{t}^{L}\right)$, of the airlines can be defined, respectively, as follows:

$$
\begin{aligned}
& \mathrm{TR}\left(I_{t}^{P}+I_{t}^{L}\right) \\
&= \sum_{\forall F_{i}, \phi \in \Phi} c_{\phi, F_{i}}\left(p_{\phi, F_{i}}^{*}\right) f_{i, F_{i}}^{t}\left(D_{t, F_{i}}^{S}, A_{t}^{i}\right) \\
&+\sum_{i=1}^{n} \sum_{y=1}^{m} \operatorname{sold}_{t i y} \text { resale }_{t i y} \text { for } t, F_{i}, i \in n, s_{h} \in S \\
& \mathrm{TC}\left(I_{t}^{P}\right.\left.+I_{t}^{L}\right) \\
&= \sum_{\forall F_{i}, \phi \in \Phi} v_{\phi, F_{i}}\left(p_{\phi, F_{i}}^{*}\right) f_{n, F_{i}}^{t}\left(D_{t, F_{i}}^{S}, A_{t}^{n}\right) \\
&+\sum_{i=1}^{n} u_{t i}+\left(\mathrm{purc}_{t i}\right)\left(x_{t i}^{P}\right)+\sum_{i=1}^{n} \operatorname{lease}_{t i}\left(x_{t i}^{L}\right) \\
&+\sum_{i=1}^{n} h g\left(D_{t, F_{i}}^{S}, A_{t}^{i}\right)+\sum_{i=1}^{n} \sum_{y=1}^{m}\left(I_{t i y}^{P}\right)\left(\mathrm{dep}_{t i y}^{P}\right) \\
&+\sum_{i=1}^{n} \sum_{y=1}^{m}\left(I_{t i y}^{L}\right)\left(\mathrm{dep}_{t i y}^{L}\right)+\sum_{i=1}^{n} \mathrm{dp}_{t i}\left(x_{t i}^{P}\right) \\
&+\sum_{i=1}^{n} \mathrm{dl}_{t i}\left(x_{t i}^{L}\right)+\sum_{i=1}^{n} C\left(\text { fuel }_{t i}\right)+\sum_{\forall F_{i}} C_{F_{i}}, \\
& \text { for } t, F_{i}, i \in n, s_{h} \in S .
\end{aligned}
$$

As shown in (19), the total operating cost of the airline, $\mathrm{TC}\left(I_{t}^{P}+I_{t}^{L}\right)$, is composed of the expected operational cost, aircraft acquisition cost (including the corresponding setup cost), aircraft leasing cost, maintenance cost, depreciation cost (for acquired and leased aircraft), payable deposit for aircraft acquisition and leasing, total fuel expenses, and total slot price (for slot purchase).

Mathematically, the fleet planning decision model for $t=1, \ldots, T$ which is in the form of a probabilistic dynamic programming model can be presented as follows:

$$
\begin{aligned}
& P\left(I_{t}^{P}+I_{t}^{L}\right)=\max _{X_{t}}\left(1+r_{t}\right)^{-t} \\
& \cdot\left\{p_{s_{1}}\left(\operatorname{TR}\left(I_{t}^{P}+I_{t}^{L}\right)-\mathrm{TC}\left(I_{t}^{P}+I_{t}^{L}\right)\right)+\cdots\right. \\
& \quad+p_{s_{h}}\left(\operatorname{TR}\left(I_{t}^{P}+I_{t}^{L}\right)-\operatorname{TC}\left(I_{t}^{P}+I_{t}^{L}\right)\right) \\
& \left.\quad+P\left(I_{t+1}^{P}+I_{t+1}^{L}\right)\right\} .
\end{aligned}
$$

The developed model is solved optimally subject to the practical constraints (8)-(17). The optimal decision of the model is the optimal quantity of the respective aircraft type to be acquired (via acquisition/leasing). By solving this model optimally, the service frequency of each operating route (under stochastic demand) could also be determined strategically.

\section{Solution Method}

4.1. Stage 1: Slot Purchase Decision Model. With the aim of providing a desired service frequency to meet stochastic demand, the slot purchase decision model can be solved optimally based on the maximum revenue generated by the prospective operating route that qualifies for slot purchase. In other words, among the potential operating routes that require slot purchase, the one which produces the utmost revenue is selected optimally in making slot purchase decision (subject to the practical constraints). It is important to note that the revenue of the respective operating route (for slot purchase consideration) is greatly influenced by the airfare of business and economy (full fare or discounted fare) class. The level of travel demand, which is fluctuating, also has a significant impact on generating the total revenue.

To optimize the slot purchase decision model, let $\omega=$ $\left\{R_{t, F_{i}}, \forall F_{i} \in F_{\text {ex }}, F_{\text {nw }}\right\}$ be the set of revenues generated by the operating route, $F_{i} \in F_{\mathrm{ex}}, F_{\mathrm{nw}}$, in the current and new operating networks. Mathematically, the optimal solution for the slot purchase decision model could be written as $R_{t, F_{i}}^{*}$ which signifies the optimum (maximum) revenue of the selected (optimal) operating route, $F_{i}^{*} \in F_{\mathrm{ex}}, F_{\mathrm{nw}}$. This implies that the optimal operating route $F_{i}^{*}$ generates the greatest revenue compared to other operating routes; that is, $R_{t, F_{i}}^{*}>R_{t, F_{i}}$ for $F_{i} \in F_{\text {ex }}, F_{\text {nw }}$. The optimal revenue, $R_{t, F_{i}}^{*}$, is subsequently included in stage 2 as part of the expected income of the airline. In other words, the optimal slot purchase decision would contribute to and increase the operational income of the airline (in stage 2). Correspondingly, additional service frequency, $\mathrm{A} f_{n, F_{i}}^{t}$, that is available from slot purchase decision (i.e., contributed by $F_{i}^{*} \in F_{\mathrm{ex}}, F_{\mathrm{nw}}$ ) is incorporated necessarily in aircraft operations which are constraint to optimize the fleet planning decision model.

4.2. Stage 2: Fleet Planning Decision Model. The proposed fleet planning model can be optimized with the aid of a decomposition approach by partitioning it into a series of simpler subproblems. To do this, the subproblem of the last operating period, $T$, is solved first (i.e., with a backward working method). This is followed by solving the problem at the period of $T-1, T-2, \ldots, 1$ so that the aircraft acquisition and leasing decision can be determined optimally. To solve the fleet planning problem, the type of solution method, that is, linear programming problem or nonlinear programming problem, can be identified accordingly based on the objective function and the practical constraints. The linearity of the developed model is primarily driven by the operational data of the airline. For validation purposes, regression testing (with the aid of mathematical software) is required.

To solve the fleet planning decision model in stage 2 , the decision variable is greatly affected by the demand constraint. 
In case the change in demand is nonpositive, the lower bound (LB) of the solution is 0 . This is because the decision variable is defined as nonnegative, that is, $x_{t i}^{P}, x_{t i}^{L} \geq 0$, and the total number of $n$ types of aircraft to be purchased and leased is also nonnegative, that is, $\sum_{i=1}^{n} x_{t i}^{P}+x_{t i}^{L} \geq 0$, for a particular operating period. In case the change in demand is positive, the lower bound is governed by the demand constraint in order to ensure that the fleet supply must meet the stochastic demand at a desired service level. However, the upper bound (UB), that is, the maximum of aircraft that could be purchased/leased, is subject to the aircraft availability in the market which is expressed as an order delivery constraint. To summarize, the lower bound, LB, of the fleet planning model can be outlined as follows:

$$
\mathrm{LB}= \begin{cases}X_{t}^{P}=0, X_{t}^{L}=0 & \text { if } \Delta D_{t}^{S} \leq 0 \\ \left(\sum_{i=1}^{n} \operatorname{LF}_{i, F_{i}}^{t}\left(\operatorname{SEAT}_{i, F_{i}}^{t}\right)\left(f_{i, F_{i}}^{t}\left(D_{t, F_{i}}^{S}, A_{t}^{i}\right)\right) \geq(1-\alpha) D_{t}^{S}\right) \cap\left(x_{t i}^{P} \leq \mathrm{ORDER}_{t}\right) & \text { if } \Delta D_{t}^{S}>0,\end{cases}
$$

where $\Delta D_{t}^{S}$ indicates the change of demand; that is, $\Delta D_{t}^{S}=$ $D_{t}^{S}-D_{t-1}^{S}$.

Let $\Omega=\left\{X_{t}: \mathrm{LB} \leq X_{t} \leq \mathrm{UB}\right\}$, where $X_{t}^{P}, X_{t}^{L} \subseteq X_{t}$ is the set of decision variables of the fleet planning decision model, and let the operational profit be $P\left(I_{t}^{P}+I_{t}^{L}\right)$, where $\Omega \subseteq I_{t}^{P} \cup I_{t}^{L}$. The optimal solution could be written as $P^{*}\left(I_{t}^{P^{*}}+I_{t}^{L^{*}}\right)$, where $P^{*}$ is the maximum profit for which $I_{t}^{P^{*}}$ and $I_{t}^{L^{*}}$ denote the corresponding quantity of aircraft that maximizes $P\left(I_{t}^{P}+I_{t}^{L}\right)$. As such, the optimal profit can be written as

$$
P^{*}\left(I_{t}^{P^{*}}+I_{t}^{L^{*}}\right)=\max _{I_{t}} P\left(I_{t}^{P}+I_{t}^{L}\right) .
$$

\section{An Illustrative Case Study}

For a set of origin-destination (OD) pairs throughout a planning horizon of 8 years, five types of aircraft, that is, B737-400, B737-800, B777-200, A330-300, and A380, are considered. These aircraft are selected based on the fleet composition operated by the airline [36] in servicing 38 international routes. According to some airlines [37-39], the aircraft acquisition requires a duration of 5 years, on average, to be delivered completely. Besides, it is assumed that the desired lead time is normally distributed with DLT $N(3,1.5)$, that is, with an average of 3 years and a standard deviation of 1.5 . As such, it is reasonably practical to consider 5 types of aircraft for a planning horizon of 8 years. The relevant data of aircraft is also compiled accordingly for data analysis $[14,40]$ besides the standard operation hours of aircraft at the respective airports for which only 4 airports (i.e., Amsterdam, Frankfurt, London, and Paris airport) were considered due to the fact that the slot control is commonly applied in Europe and the United States [17]. For the new network expansion, the level of travel demand of short-haul route (\#1), medium-haul route (\#2), and long-haul route (\#3) was compiled accordingly based on the average value of the existing operating networks and 5-step stochastic demand modeling framework of Khoo and Teoh [26]. In addition, other data inputs are listed as

(i) discount rate, $r_{t}=5 \%$,

(ii) load factor, $\mathrm{LF}_{n, F_{i}}^{t}=70 \%$, (iii) significance level of demand constraint, $\alpha=10 \%$,

(iv) significance level of lead time constraint, $\beta=5 \%$,

(v) significance level of selling time constraint, $\gamma=5 \%$,

(vi) portion of passengers in business class, $\mathrm{Biz}_{\%}=12 \%$,

(vii) portion of passengers in economy class (full fare), $\mathrm{Fec}_{\%}=20 \%$,

(viii) portion of passengers in economy class (discounted fare), $\mathrm{Dec}_{\%}=80 \%$,

(ix)

$$
\begin{aligned}
& D_{t}^{s_{1}}=D_{t}, \\
& D_{t}^{s_{h}}=(1-\alpha) D_{t}^{s_{h-1}}
\end{aligned}
$$

$$
\text { for } t=1, \ldots, T ; h>1 \text {, }
$$

(x) the probability of possessing aircraft being $p_{s_{1}}=0.50$, $p_{s_{2}}=0.36$, and $p_{s_{3}}=0.14$,

(xi) at $t=1$, initial quantity of aircraft to be 4 years old being $I_{1 i 4}^{P}=2$ for $i=1,2,3,4$,

(xii) setup cost to acquire $n$ types of new aircraft, $u_{t i}=0$ for $i=1,2, \ldots, n$,

(xiii) maximum utilization of aircraft, $\mathrm{MXU}_{n, F_{i}}^{t}=105 \% \times$ (actual aircraft utilization),

(xiv) annual aircraft availability, $\operatorname{AVT}_{n, F_{i}}^{t}=340$ days,

(xv) slot price, $C_{F_{i}}=\$ 5$ million,

(xvi) airline's willingness to pay, $W_{F_{i}}=\$ 6$ million,

(xvii) allocated budget, $\operatorname{MAX}_{\text {budget }(t)}=\$ 6,500$ million,

(xviii) area of parking space, $\mathrm{PARK}_{t}=500,000 \mathrm{~m}^{2}$,

(xix) order delivery constraint, $\mathrm{ORDER}_{t}=5$,

$(\mathrm{xx})$ salvage cost of aircraft $=10 \% \times \mathrm{PURC}_{t}$,

(xxi) deposit of aircraft acquisition, $\mathrm{DP}_{t}=10 \% \times \mathrm{PURC}_{t}$,

(xxii) deposit of aircraft leasing, $\mathrm{DL}_{t}=10 \% \times \mathrm{LEASE}_{t}$,

(xxiii) network efficiency factor, $\mathrm{EFF}_{t}=60 \%$,

(xxiv) turnround time, $\mathrm{TUN}_{n, F_{i}, k}^{t}=40$ minutes, 
$(\mathrm{xxv})$ the function of maintenance cost being

$$
h=5177+7.97 \times 10^{-3} g \quad\left[R^{2}=0.94\right],
$$

where $g$ is the traveled mileage,

(xxvi) the quantity of aircraft being

$$
\mathrm{NA}=10^{-5} \mathrm{NP}-73.6 \quad\left[R^{2}=0.92\right],
$$

where NP is the number of travelers,

(xxvii) the function of fuel expenses being

$$
\begin{array}{r}
C\left(\text { fuel }_{t n}\right)=7.46 f+8.3 \times 10^{-5} f^{2}-98,572 \\
\quad\left[R^{2}=0.88\right],
\end{array}
$$

where $f$ refers to the service frequency of a particular operating route.

In order to assure an adequate fleet supply, three possible phenomena, that is, $h=3$, are considered to account for the operational, economic, and environmental aspects. As reported by the airlines [37, 38], the operational and economic aspects are 2 major concerns in fleet planning. Additionally, the environmental aspect is required to be included due to increasing concern about it and its crucial impacts on the airline's operations.

\section{Results and Discussions}

As mentioned earlier, the slot purchase decision-making is determined based on the optimal revenue of each operating period throughout the long-term planning horizon; that is, the optimal revenue is contributed by the operating route (for the current and new networks) which is to be operated under the slot purchase decision-making. It was found that the long-haul flight from KL to London (KL-London) in the current operating network emerges as the most gainful operating route while long-haul route \#3 appears to be the new operating route (for new network expansion) that produces the utmost revenue in optimizing the slot purchase decision-making (in stage 1). The results of the proposed two-stage fleet planning model are summarized in Table 1. Specifically, the results suggest the airline to operate a new network (for long-haul route \#3) in year 2 and this would contribute a total of 39 operating routes throughout the planning horizon.

As shown in Table 1, the slot purchase decision-making would provide more (additional) service frequency, that is, a total of 323 flights per annum (for the current operating network to support the KL-London route and also a new network to operate long-haul route \#3). In particular, the results signify that the KL-London flight will secure more slots, that is, 42 flights (the average per annum). In other words, the airline may offer at least 2 flights per day to meet the increasing demand (in view of the fact that the daily flight frequency of the KL-London flight is 2 in accordance with the operational data of the airline in the case study).
TABLE 1: The computational results of case study.

Slot purchase decision

Current operating network:

Slot purchase decision for KL-London route Years 1, 2, 4, 6, 7, 8

New operating network:

Slot purchase decision for long-haul rote \#3 Year 2

Revenue and profit

Total annual revenue, \$ (contributed by slot purchase decision)

(i) Current operating network

$67,406,638$

(ii) New operating network

$33,912,947$

Annual profit of airline, \$

$33,493,691$

Demand

Total annual demand (met by slot purchase decision)

$589,667,623$

(i) Current operating network

66,460

(ii) New operating network

29,045

Average demand level of airline

37,415

Service frequency

Total annual service frequency (provided by

slot purchase decision)

$4,064,316$

(i) Current operating network

323

(ii) New operating network

42

Average service frequency of airline (per annum)

281

\begin{tabular}{lc}
\hline Fleet planning decision & \\
Fleet size (at the end of year 8) & 56 \\
B737-400 & 18 \\
B737-800 & 16 \\
B777-200 & 6 \\
A330-300 & 12 \\
A380 & 4 \\
Quantity of purchased aircraft : leased aircraft & $48: 8$ \\
\hline
\end{tabular}

Correspondingly, the demand level met by making such slot purchase decision appears to be higher in average; that is, it is approximated to be 66,460 more (per annum). This signifies that the airline could meet a higher level of stochastic demand by providing more service frequency via the optimal slot purchase decision. This finding is in line with the facts as revealed by Brueckner [18], Fukui [21], and Babic and Kalic [11, 12]. Consequently, more profit could be obtained by the airline due to the contribution of a higher level of revenue which is mainly generated by additional flights (which resulted from the slot purchase decision of KLLondon and \#3 flight). This shows that, by making an optimal slot purchase decision, a higher demand level could be met by the airlines at a more profitable level. The results in Table 1 show that a higher flight frequency to meet more travel demand would result in an additional revenue of $\$ 67$ million (average value per annum), which consequently contributes about $\$ 590$ million of profit (per annum). A similar fact 
which shows that slot purchase is useful for airlines to assure more profit could be seen in Babic and Kalic [11, 12].

For the current operating network, Table 1 shows that the airline did not make any slot purchase decision for operating years 3 and 5. This could be explained by the level of stochastic demand that is estimated to drop about $32 \%$ in year 3 . For year 5 , there is no demand increment (compared to previous year, i.e., year 4) and hence the slot purchase decision did not apply to these operating periods. Under these circumstances, the airline may consider selling or leasing the slot to other airlines for additional income [21]. This shows that the developed model is able to provide insightful information to airlines at the right time to make relevant slot purchase decision throughout the long-term planning horizon.

In order to provide a higher service frequency (via slot purchase decision) to meet the stochastic demand, the results indicate that the airline would tend to acquire/lease more aircraft to support the current and new operating networks. In accordance with the slot purchase decision to service KLLondon route and long-haul flight \#3, two jumbo A380 are leased mainly due to their availability in supporting long-haul routes at a more economical aircraft acquisition/leasing cost per seat. This signifies that there is a positive relation between the slot purchase decision and fleet planning decision of airlines for which the slot purchase decision-making that basically aims to provide a higher service frequency to meet more demand would practically require more aircraft (via acquisition/leasing) for services. Yet the quantity of the respective aircraft type that is needed for additional operations depends very much on the operating route and the demand level to be serviced via slot purchase; for example, $\mathrm{KL}$-London route as well as long-haul route \#3 would require more jumbo aircraft (A380). In other words, it could be inferred that there is a tendency for airlines to acquire/lease fewer aircraft if the slot purchase decision is not taken into consideration.

Apparently, it could be empirically deduced that demand increment influences the slot purchase decision positively and it is observable that the slot purchase has a positive impact on service frequency and fleet supply as well as the profit level of airlines. This shows that slot purchase has a direct and closed linkage not only with the aspect of demand but also with the aspect of supply, which are relatively vital for demand-supply management. More importantly, the results show that the incorporation of slot purchase in fleet planning is beneficial to airlines in achieving economic and social sustainability. This is practically viable for airlines to provide a better service quality via a higher service frequency in meeting more demand (social aspect) as well as to obtain a higher revenue and profit (economic aspect) by making optimal slot purchase and fleet planning decision.

The consistency and stability of the resultant findings could be empirically confirmed by comparing the results with the operational statistics of the airline [36]. Comparatively, it was found that the fleet size of MAS falls within the range of 2 standard deviations from its average (for the years 2006-2012). Similar pattern could be observed for the service frequency determination of airline. Therefore, it could be empirically deduced that the solutions obtained from the developed model are coherent with the operating performance of airline. As such, the results in this paper are consistent with the actual practice and hence the stability of the findings (and also the developed model) could be empirically confirmed.

\section{Conclusions}

This paper has developed a novel approach to solve the long-term fleet planning problem under stochastic demand. A two-stage fleet planning model is formulated for which the aim of stage 1 (slot purchase decision model) is to select an individual operating route (at optimal revenue) that necessitates slot purchase for network expansion. Mathematically, stage 2 (fleet planning decision model) aims to obtain the maximum profit of airlines, by determining the optimal quantity of the respective aircraft type (with corresponding service frequency) that has to be purchased/leased throughout the long-term planning horizon. The results of a realistic case study, with 38 international routes, reveal that slot purchase is beneficial to airlines in assuring a higher profit level. This could be achieved when a higher level of travel demand is met by providing more service frequency (with optimal slot purchase decision). By incorporating slot purchase in fleet planning, it was also found that the airline would tend to acquire/lease more aircraft, yet the quantity and aircraft type depend on the specific operating route that requires slot purchase. The proposed study, in fact, reflects the actual scenario of the airline industry which includes the challenges of providing desired service frequency (by incorporating slot purchase) to meet the stochastic demand of the practical issues in acquiring/leasing adequate fleet supply to support the entire operating system. For future research, this study could be extended by considering aircraft pollution constraint in response to the environmental issue which is receiving greater concern nowadays.

\section{Abbreviations}

\section{Parameters}

\begin{tabular}{|c|c|}
\hline$T:$ & Planning horizon \\
\hline $\operatorname{MAX}_{\text {budget }(t)}$ : & $\begin{array}{l}\text { Allocated budget to acquire/lease } \\
\text { aircraft }\end{array}$ \\
\hline $\mathrm{ORDER}_{t}:$ & $\begin{array}{l}\text { Quantity of aircraft that could be } \\
\text { purchased in the market }\end{array}$ \\
\hline $\mathrm{PARK}_{t}$ : & Area of hangar/apron \\
\hline$r_{t}:$ & $\begin{array}{l}\text { Discount rate (with the discount factor } \\
\left.\left(1+r_{t}\right)^{-t}\right)\end{array}$ \\
\hline$\alpha, \beta, \gamma:$ & $\begin{array}{l}\text { Significance level of demand, lead time, } \\
\text { and selling time constraint, respectively }\end{array}$ \\
\hline$\phi:$ & $\begin{array}{l}\text { Class of passengers (biz for business } \\
\text { class, fec for economy full-fare class, and } \\
\text { dec for economy discounted fare class) }\end{array}$ \\
\hline$p_{s}:$ & $\begin{array}{l}\text { Probability of having } I_{t}^{P} \text { and } I_{t}^{L} \\
\text { (corresponding to phenomenon } S \text { ) }\end{array}$ \\
\hline$A_{t}^{n}:$ & Total operated aircraft \\
\hline $\operatorname{MAX}_{F(t)}$ : & $\begin{array}{l}\text { Total number of operating routes in } \\
\text { year } t\end{array}$ \\
\hline
\end{tabular}


$F_{i}$ : $\quad$ Operating route (flight) for which

$i=1,2, \ldots, \operatorname{MAX}_{F(t)}$

$F_{\text {ex }}: \quad$ Current operating network

$F_{\text {nw }}$ : New operating network

SEAT $_{n, F_{i}}^{t}$ : Seat (capacity) of aircraft

$f_{n, F_{i}}^{t}$ : $\quad$ Service frequency of aircraft $n$ that is servicing operating route $F_{i}$ in year $t$

$\mathrm{E}\left(f_{F_{i}}^{t}\right): \quad$ Estimated service frequency of operating route $F_{i}$ in year $t$

$\mathrm{A} f_{n, F_{i}}^{t}: \quad$ Additional service frequency of operating route $F_{i}$ (resulting from slot purchase decision-making)

$D_{t, F_{i}}^{S}$ : $\quad$ Demand level of operating route $F_{i}$ (corresponding to phenomenon $S$ )

$\mathrm{LF}_{n, F_{i}}^{t}: \quad$ Load factor of aircraft $n$

$g_{n, F_{i}}: \quad$ Traveled mileage of operating route $F_{i}$

$\mathrm{NP}_{n, F_{i}}: \quad$ Number of passengers of operating route $F_{i}$

$\mathrm{MXU}_{n, F_{i}}^{t}$ : Maximum utilization of aircraft (in terms of service frequency)

$\mathrm{EFF}_{t}$ : Network efficiency factor

$\mathrm{AVT}_{n, F_{i}}^{t}$ : Aircraft availability (in number of days)

$\mathrm{BLK}_{n, F_{i}}^{t}$ : Block time of operating route $F_{i}$ (in hours and minutes)

$\mathrm{TUN}_{n, F_{i}, k}^{t}$ : Turnround time at airport $k$ (in minutes)

$C_{F_{i}}$ : $\quad$ Slot price of flight (operating route $F_{i}$ )

$W_{F_{i}}$ : Airline's willingness to pay for the slot purchase of operating route $F_{i}$

$c_{\phi, F_{i}}: \quad$ Airfare of the respective class of passenger

$c_{\mathrm{biz}, F_{i}}: \quad$ Airfare of business class

$c_{\mathrm{fec}, F_{i}}$ : Airfare of economy class (full fare)

$c_{\mathrm{dec}, F_{i}}: \quad$ Airfare of economy class (discounted fare)

$p_{\phi, F_{i}}^{*}$ : $\quad$ Number of passengers in the respective class of passenger

$p_{\mathrm{biz}, F_{i}}^{*}: \quad$ Number of passengers in business class

$p_{\mathrm{fec}, F_{i}}^{*}$ : Number of passengers in economy class (with full fare)

$p_{\mathrm{dec}, F_{i}}^{*}: \quad$ Number of passengers in economy class (with discounted fare)

$\Delta p_{\mathrm{biz}, F_{i}}^{*}: \quad$ Number of passengers (business class) to be met with slot purchase decision

$\Delta p_{\mathrm{fec}, F_{i}}^{*}$ : Number of passengers (economy full fare) to be met with slot purchase decision

$\Delta p_{\mathrm{dec}, F_{i}}^{*}$ : Number of passengers (economy discounted fare) to be met with slot purchase decision

$\mathrm{Biz}_{\%}$ : $\quad$ Portion (percentage) of passengers in business class

$\mathrm{Fec}_{\%}$ : $\quad$ Portion (percentage) of passengers in economy class (full fare)

$\mathrm{Dec}_{\%}$ : $\quad$ Portion (percentage) of passengers in economy class (discounted fare)

open: Start of working hours at airport

close: End of working hours at airport
$\mathrm{RG}_{n}$ : Aircraft range (maximum distance flown of aircraft $n$ )

DIS $_{F_{i}}$ : Distance of operating route $F_{i}$

$b_{\text {ex }}$ : Binary variable of current operating networks

$b_{\mathrm{nw}}$ : Binary variable of new operating network

$v_{\phi, F_{i}}$ : Operating cost of the respective class of passenger (i.e., $v_{\text {biz }, F_{i}}$ for business class; $v_{\mathrm{dec}, F_{i}}$ for discounted cost of economy class; and $v_{\mathrm{fec}, F_{i}}$ for full cost of economy class).

Functions

$P\left(I_{t}^{P}+I_{t}^{L}\right): \quad$ Discounted profit function by having $I_{t}^{P}$ and $I_{t}^{L}$

$h g\left(D_{t, F_{i}}^{S} ; A_{t}^{n}\right): \quad$ Function of maintenance cost in terms of traveled mileage, $g$

$C\left(\right.$ fuel $\left._{t n}\right): \quad$ Fuel expenses function

$f_{n, F_{i}}^{t}\left(D_{t, F_{i}}^{S} ; A_{t}^{n}\right)$ : Function of service frequency in terms of demand, $D_{t, F_{i}}^{S}$, and total operated aircraft, $A_{t}^{n}$.

Sets

$X_{t}^{P}=\left(x_{t 1}^{P}, x_{t 2}^{P}, \ldots, x_{t n}^{P}\right): \quad$ Quantity of aircraft

$X_{t}^{L}=\left(x_{t 1}^{L}, x_{t 2}^{L}, \ldots, x_{t n}^{L}\right)$ :

$I_{t}=\left(I_{t 1 y}, I_{t 2 y}, \ldots, I_{t n y}\right)$ : to be purchased Quantity of aircraft to be leased Initial quantity of aircraft

$I_{t}^{P}=\left(I_{t 1 y}^{P}, I_{t 2 y}^{P}, \ldots, I_{t n y}^{P}\right):$

$I_{t}^{L}=\left(I_{t 1 y}^{L}, I_{t 2 y}^{L}, \ldots, I_{t n y}^{L}\right)$ : (purchased/leased) Initial quantity of purchased aircraft Initial quantity of leased aircraft

$U_{t}=\left(u_{t 1}, u_{t 2}, \ldots, u_{t n}\right):$ Setup cost for aircraft acquisition $S=\left(s_{1}, s_{2}, \ldots, s_{h}\right): \quad$ Phenomenon of

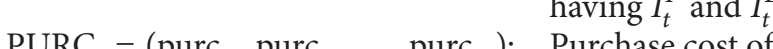
Purchase cost of aircraft

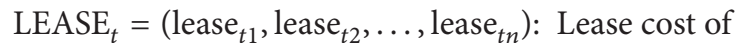
aircraft

$\mathrm{DP}_{t}=\left(\mathrm{dp}_{t 1}, \mathrm{dp}_{t 2}, \ldots, \mathrm{dp}_{t n}\right): \quad$ Payable deposit for aircraft acquisition

$\mathrm{DL}_{t}=\left(\mathrm{dl}_{t 1}, \mathrm{dl}_{t 2}, \ldots, \mathrm{dl}_{t n}\right): \quad$ Payable deposit for aircraft leasing

$\mathrm{SOLD}_{t}=\left(\operatorname{sold}_{t 1 y}, \operatorname{sold}_{t 2 y}, \ldots\right.$, sold $\left._{t n y}\right):$ Quantity of aircraft sold

$\operatorname{RESALE}_{t}=\left(\right.$ resale $_{t 1 y}, \ldots$, resale $\left._{t n y}\right): \quad$ Resale price of aircraft

$\operatorname{DEP}_{t}^{P}=\left(\operatorname{dep}_{t 1 y}^{P}, \operatorname{dep}_{t 2 y}^{P}, \ldots, \operatorname{dep}_{t n y}^{P}\right): \quad$ Depreciation value of purchased aircraft 


$$
\begin{array}{ll}
\operatorname{DEP}_{t}^{L}=\left(\operatorname{dep}_{t 1 y}^{L}, \operatorname{dep}_{t 2 y}^{L}, \ldots, \operatorname{dep}_{t n y}^{L}\right): & \begin{array}{l}
\text { Depreciation value } \\
\text { of leased aircraft }
\end{array} \\
\operatorname{SIZE}^{L}=\left(\operatorname{size}_{1}, \operatorname{size}_{2}, \ldots, \operatorname{size}_{n}\right): & \text { Aircraft size } \\
\operatorname{DLT}_{t}=\left(\mathrm{DLT}_{t 1}, \mathrm{DLT}_{t 2}, \ldots, \mathrm{DLT}_{t n}\right): & \begin{array}{l}
\text { Desired lead time of } \\
\text { aircraft acquisition }
\end{array} \\
\mathrm{DST}_{t}=\left(\mathrm{DST}_{t 1}, \mathrm{DST}_{t 2}, \ldots, \mathrm{DST}_{t n}\right): \begin{array}{l}
\text { Desired selling time } \\
\text { of aging aircraft }
\end{array} \\
\Phi=(\mathrm{biz}, \mathrm{fec}, \mathrm{dec}): & \begin{array}{l}
\text { Classification of } \\
\text { passengers. }
\end{array}
\end{array}
$$

\section{Competing Interests}

The authors declare that they have no competing interests.

\section{Acknowledgments}

The authors would like to express their gratitude to the Ministry of Education (MOE) for supporting this research study under the Fundamental Research Grant Scheme [FRGS/1/2012/TK08/UTAR/03/3].

\section{References}

[1] J. Zak, A. Redmer, and P. Sawicki, "Multiple objective optimization of the fleet sizing problem for road freight transportation," Journal of Advanced Transportation, vol. 42, no. 4, pp. 379-427, 2008.

[2] P. Czyzak and J. Zak, "A model of an urban transportation system formulated as a multiobjective mathematical programming problem under uncertainty," Journal of Advanced Transportation, vol. 29, no. 1, pp. 43-62, 1995.

[3] M. J. Penner, C. P. Duncan, and B. A. Masri, "The in vitro elution characteristics of antibiotic-loaded CMW and Palacos-R bone cements," The Journal of Arthroplasty, vol. 14, no. 2, pp. 209-214, 1999.

[4] T. G. Crainic, "Service network design in freight transportation," European Journal of Operational Research, vol. 122, no. 2, pp. 272-288, 2000

[5] C.-I. Hsu and Y.-H. Wen, "Determining flight frequencies on an airline network with demand-supply interactions," Transportation Research Part E: Logistics and Transportation Review, vol. 39, no. 6, pp. 417-441, 2003.

[6] O. Listes and R. Dekker, "A scenario aggregation-based approach for determining a robust airline fleet composition for dynamic capacity allocation," Transportation Science, vol. 39, no. 3, pp. 367-382, 2005.

[7] D. E. Pitfield, R. E. Caves, and M. A. Quddus, "Airline strategies for aircraft size and airline frequency with changing demand and competition: a simultaneous-equations approach for traffic on the north Atlantic," Journal of Air Transport Management, vol. 16, no. 3, pp. 151-158, 2010.

[8] S. Dožić and M. Kalić, "Three-stage airline fleet planning model," Journal of Air Transport Management, vol. 46, pp. 3039, 2015.

[9] C.-I. Hsu, H.-C. Li, S.-M. Liu, and C.-C. Chao, "Aircraft replacement scheduling: a dynamic programming approach," Transportation Research Part E: Logistics and Transportation Review, vol. 47, no. 1, pp. 41-60, 2011.
[10] C.-I. Hsu, C.-C. Chao, and P.-S. Huang, "Fleet dry/wet lease planning of airlines on strategic alliance," Transportmetrica A: Transport Science, vol. 9, no. 7, pp. 603-628, 2013.

[11] D. Babic and M. Kalic, "Modelling the estimation of the airline profit in case of purchasing new slots for increasing flight frequency," Procedia-Social and Behavioral Sciences, vol. 20, pp. 1069-1079, 2011.

[12] D. Babic and M. Kalic, "Airline route network expansion: modelling the benefits of slot purchases," Journal of Air Transport Management, vol. 23, pp. 25-30, 2012.

[13] Y. H. Wen, "Airline flight frequency determination and adjustment in response to airline emission charges," in Proceedings of the International Conference of Eastern Asia Society for Transportation Studies, Taipei, Taiwan, September 2013.

[14] Boeing, http://www.boeing.com/.

[15] E. Sachlos and J. T. Czernuszka, "Making tissue engineering scaffolds work. Review: the application of solid freeform fabrication technology to the production of tissue engineering scaffolds," European Cells \& Materials, vol. 5, p. 29, 2003.

[16] D. Gillen, Slot Trading in North America, Euaca Seminar on Secondary Trading Amsterdam Airport, Schiphol, The Netherlands, 2006.

[17] S. R. Mehndiratta and M. Kiefer, "Impact of slot controls with a market-based allocation mechanism at San Francisco International Airport," Transportation Research Part A, vol. 37, no. 7, pp. 555-578, 2003.

[18] J. K. Brueckner, "Price vs. quantity-based approaches to airport congestion management," Journal of Public Economics, vol. 93, no. 5-6, pp. 681-690, 2009.

[19] Q. Gao, J. Yan, and J.-F. Zhu, "Airlines' optimization decision of slot allocation in CDM," Journal of Transportation Systems Engineering and Information Technology, vol. 11, no. 5, pp. 9498, 2011.

[20] P. Swaroop, B. Zou, M. O. Ball, and M. Hansen, "Do more US airports need slot controls? A welfare based approach to determine slot levels," Transportation Research Part B, vol. 46, no. 9, pp. 1239-1259, 2012.

[21] H. Fukui, "An empirical analysis of airport slot trading in the United States," Transportation Research Part B, vol. 44, no. 3, pp. 330-357, 2010.

[22] L. J. Basso and A. Zhang, "Pricing vs. slot policies when airport profits matter," Transportation Research Part B: Methodological, vol. 44, no. 3, pp. 381-391, 2010.

[23] M. Takebayashi, "The runway capacity constraint and airlines' behavior: choice of aircraft size and network design," Transportation Research Part E: Logistics and Transportation Review, vol. 47, no. 3, pp. 390-400, 2011.

[24] D. B. Teodorović, "Flight frequency determination," Journal of Transportation Engineering, vol. 109, no. 5, pp. 747-757, 1983.

[25] M. Givoni and P. Rietveld, "The environmental implications of airlines' choice of aircraft size," Journal of Air Transport Management, vol. 16, no. 3, pp. 159-167, 2010.

[26] H. L. Khoo and L. E. Teoh, "An optimal aircraft fleet management decision model under uncertainty," Journal of Advanced Transportation, vol. 48, no. 7, pp. 798-820, 2014.

[27] M. Hansen, "Airline competition in a hub-dominated environment: an application of noncooperative game theory," Transportation Research Part B, vol. 24, no. 1, pp. 27-43, 1990.

[28] D. Teodorović, M. Kalić, and G. Pavković, “The potential for using fuzzy set theory in airline network design," Transportation Research Part B, vol. 28, no. 2, pp. 103-121, 1994. 
[29] W. Wei and M. Hansen, "Impact of aircraft size and seat availability on airlines' demand and market share in duopoly markets," Transportation Research Part E: Logistics and Transportation Review, vol. 41, no. 4, pp. 315-327, 2005.

[30] W. Wei and M. Hansen, "Airlines' competition in aircraft size and service frequency in duopoly markets," Transportation Research Part E: Logistics and Transportation Review, vol. 43, no. 4, pp. 409-424, 2007.

[31] W. Wei, "Impact of landing fees on airlines' choice of aircraft size and service frequency in duopoly markets," Journal of Air Transport Management, vol. 12, no. 6, pp. 288-292, 2006.

[32] L. E. Teoh, Optimal airline fleet planning and management strategies under stochastic demand [Ph.D. thesis], Universiti Tunku Abdul Rahman, Petaling Jaya, Malaysia, 2015, http:// eprints.utar.edu.my/1901/1/EGA-2015-0909073-1.pdf.

[33] H. A. Taha, Operations Research: An Introduction, Pearson Education, New Jersey, NJ, USA, 2003.

[34] A. Sentance, "Airport slot auctions: desirable or feasible?" Utilities Policy, vol. 11, no. 1, pp. 53-57, 2003.

[35] G. Sieg, "Grandfather rights in the market for airport slots," Transportation Research Part B, vol. 44, no. 1, pp. 29-37, 2010.

[36] Malaysia Airlines, June 2013, http://www.malaysiaairlines.com/ my/en.html.

[37] Malaysia Airlines, December 2010, http://klse.i3investor.com/ servlets/stk/annrep/3786.jsp.

[38] AirAsia Berhad, http://www.airasia.com/my/en/about-us/irannual-reports.page.

[39] AirAsia Berhad, March 2013, http://www.airasia.com.my.

[40] Airbus, http://www.airbus.com/. 


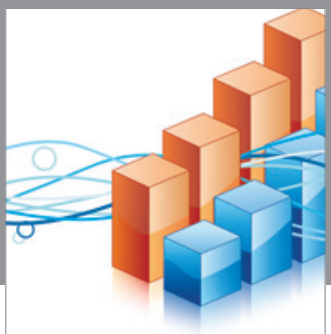

Advances in

Operations Research

vatem alat4

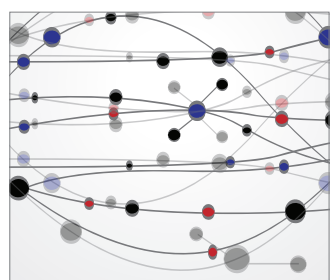

\section{The Scientific} World Journal
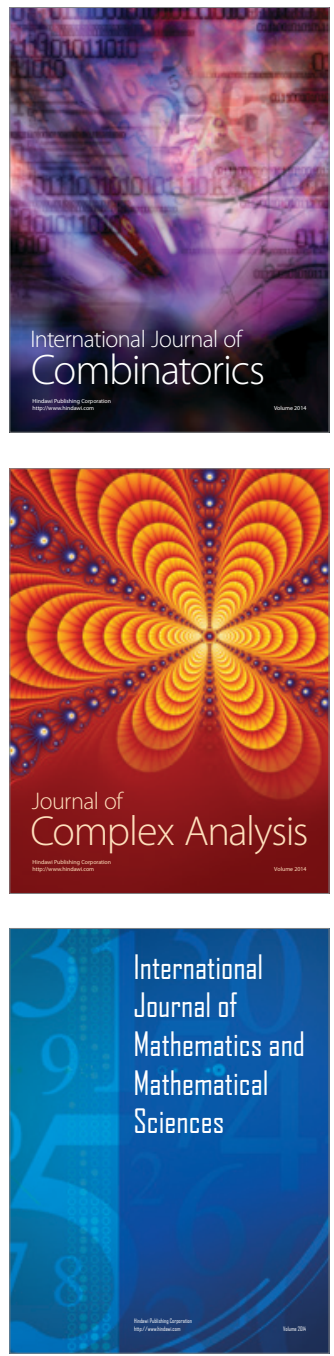
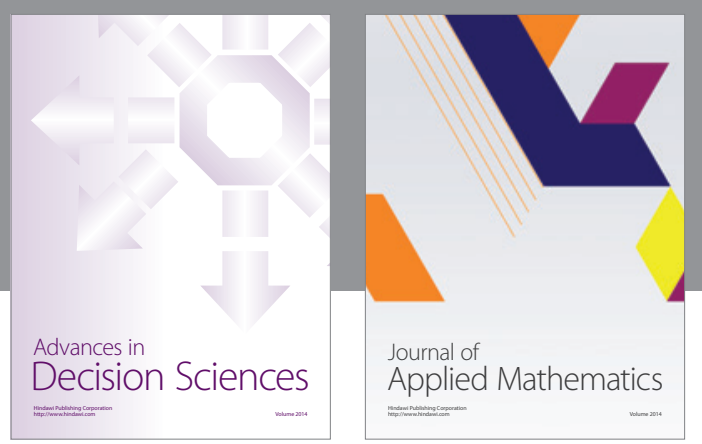

Algebra

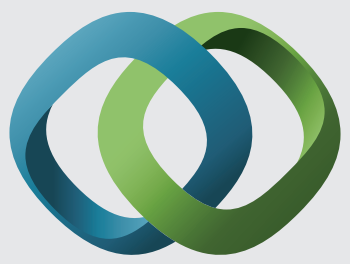

\section{Hindawi}

Submit your manuscripts at

http://www.hindawi.com
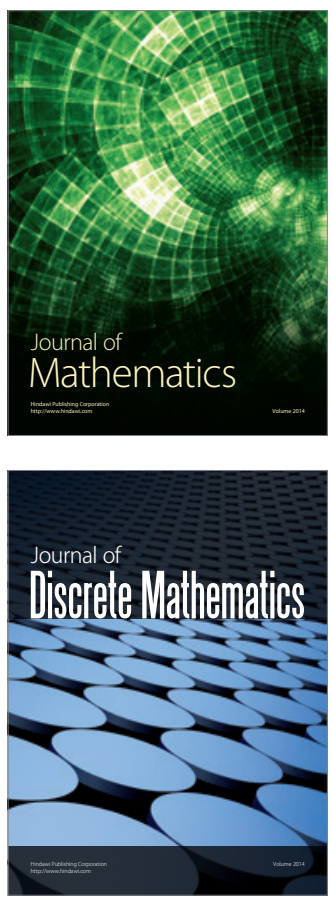

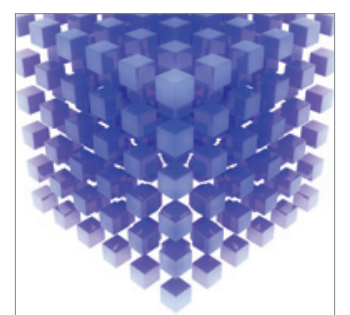

Mathematical Problems in Engineering
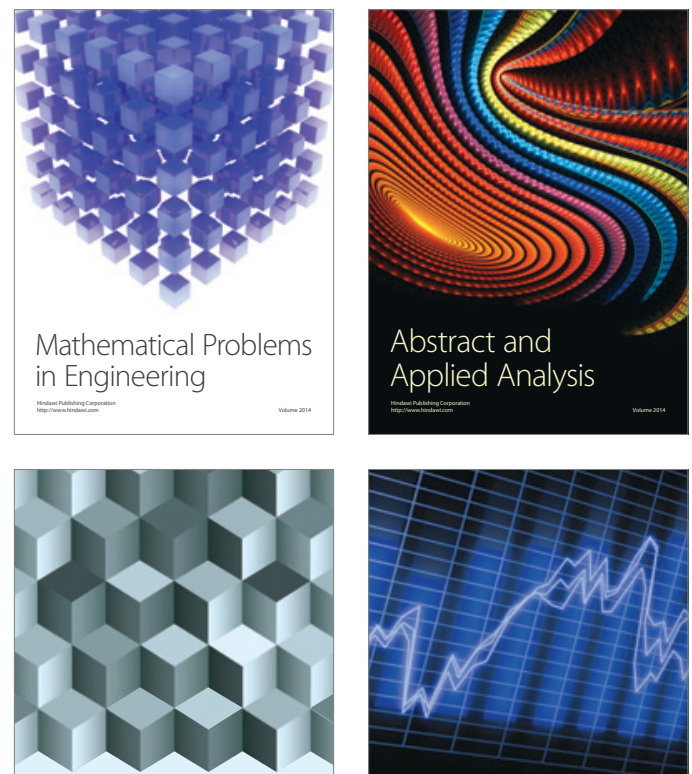

Journal of

Function Spaces

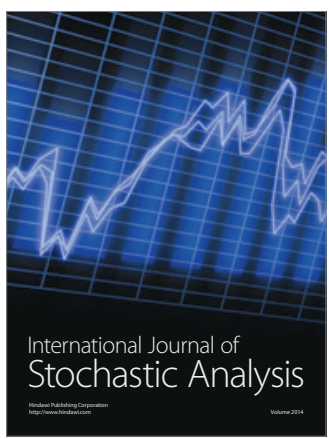

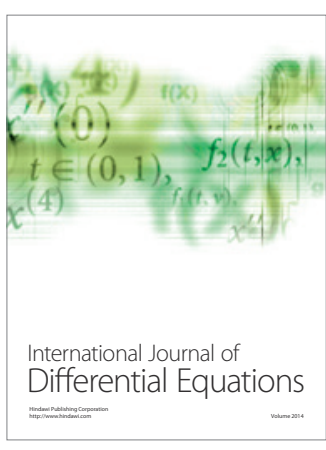
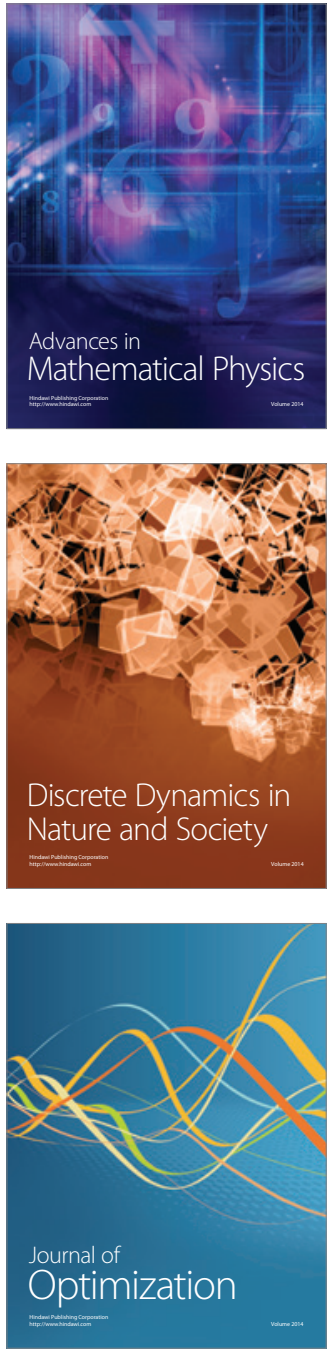